\title{
INSTITUIÇÔES E QUESTÃO AMBIENTAL: Conselhos Municipais de Meio Ambiente no Paraná
}

\author{
Prof. Ms. Fábio de Oliveira Neves \\ Doutorando em Geografia pela Univ. Federal do Paraná. Professor UNIOESTE \\ Rua Pernambuco 1777, UNIOESTE - Curso de Geografia, CEP: 85960-000, Mar. Cândido Rondon - PR, Brasil \\ Tel: (55 45) 3254.3457 / 9936.6313 - foneves@gmail.com
}

\begin{abstract}
RESUMO
As instituições estatais e a sua regulamentação sobre o território são temas indispensáveis para o estudo da relação entre a sociedade e o ambiente. Neste artigo, destaca-se a institucionalização da questão ambiental, com foco sobre a situação dos conselhos municipais de meio ambiente no Estado do Paraná, reconhecendo-os como instituições importantes na escala local, notadamente pelo seu caráter participativo. É, portanto, no município que a proximidade da política abre a possibilidade de inserção dos temas ambientais mais urgentes nas agendas locais, pelos conselhos. Assim, se aposta no desenvolvimento e na consolidação destes fóruns participativos para a definição de prioridades relacionadas à questão ambiental. Os conselhos municipais de meio ambiente são instituições bem difundidas e consolidadas no território paranaense? Estão em operação ou existem apenas formalmente? Quais são as funções destes conselhos? Estas questões fizeram parte das inquietações que originaram o artigo.
\end{abstract}

Palavras-chave: Conselhos municipais de meio ambiente, questão ambiental, instituições.

\begin{abstract}
The state institutions and their regulation over the territory are keys themes to the study of the relationship between society and the environment. This work studies the institutionalization of the environmental issue and makes a diagnosis about the local environmental councils of the Paraná State, recognizing them as important institutions in the local scale. Thus, the proximity of the local politics opens the opportunity of insert the environmental themes on the political agenda, by the councils. So, the emphasis of this article is on the development and consolidation of these participative forums to define the priorities about the environmental issue. Are local environmental councils institutions well disseminated and consolidated in the Paraná's territory? Are they in activity or exist only formally? Which are their functions? These questions form part of the concerns that gave rise to article.
\end{abstract}

Key words: Local environmental councils; environmental issue; institutions.

\section{RÉSUMÉ}

Les institutions publiques et sa réglementation sur le territoire sont des thèmes indispensables pour l'étude des relations entre la société et l'environnement. Dans cet article, on expose l'institutionalité de la question environnementale, materialisé sur la situation des conseils municipaux de l'environnement dans l'état du Parana - Brésil, parce que sont des institutions importants dans l'échelle locale, pour sa caractéristique participative. Dans cette échelle, la proximité de la politique ouvre la possibilité de l'insersion du thème environnemental dans le discussion publique, pour les conseils. Ces sont centrales pour le développement et la consolidation des forums participatifs pour la définition des priorités des populations. Les conseils municipaux de l'environment sont institutions bien distribués et consolidés dans le territoire du Parana? Ils sont en fonctionnement ou ils n'existent que formalement? Quels sont les attributions des conseils? Ces questions font part de les inquiétudes que donne origine au article.

Mots-clés: Conseils municipaux de l'environnement, question environnementale, institutions.

\section{INTRODUÇÃO}

A atividade humana sobre a superfície é relevante para a questão ambiental contemporânea? O homem tem papel importante nas alterações climáticas e na degradação de ecossistemas? Se as respostas são positivas, não é possível deslocar o papel de protagonista do homem da problemática ambiental no século XXI.

Muitas vezes, apesar de se afirmar a complexidade da questão ambiental, não se evidencia que o homem é o protagonista desse jogo. Esta pesquisa refuta as orientações naturalistas, que vêem o homem como apenas uma variável, e propõe desenvolver reflexões que incluam, de um lado, o território, seus conflitos e práticas de apropriação de recursos e, de outro, a política, como modo de controle e gestão desses conflitos. Território e política compõem o campo de trabalho da Geografia Política. 
De que modo a Geografia Política poderia contribuir com os estudos sobre a questão ambiental? Nesse contexto, é importante atentar para a temática das instituições que regulam o território, seu uso e as atividades praticadas sobre ele. Tema no qual se insere a Geografia Política e, por conseguinte, o Estado e o seu aparato político-institucional.

Apesar das críticas dirigidas a ele e das tendências desestatizantes das últimas décadas, o Estado aparece como o regulamentador do território e dos conflitos ambientais. Assim, questiona-se qual é a resposta do Estado para as demandas ambientais da sociedade. Estas respostas podem resultar no surgimento de instituições específicas que lidam com essa questão. São secretarias, ministérios, conselhos, partidos políticos, enfim, instituições que incorporam essas demandas. É necessário, portanto, pesquisar sobre o desenvolvimento institucional referente ao meio ambiente.

O Brasil conta com um arranjo institucional complexo e coordenado pelo Sistema Nacional do Meio Ambiente (SISNAMA), que busca a organização da cooperação entre as diferentes escalas de poder: a nacional, a estadual e a local (ou municipal).

A escala local é aquela em que os danos ambientais se tornam mais evidentes no cotidiano do cidadão. É quando este sente diretamente os malefícios da degradação de uma área que a atenção desloca-se de necessidades mais tradicionais, com destaque para as de origem econômica, para a preocupação relacionada ao meio ambiente.

No aparato estatal, o município é o ente federativo que está mais próximo ao cidadão, para acolher suas demandas. Este, contudo, depende do desenvolvimento institucional para atendê-las. Não só das instituições que elaboram as leis e intervêm no território, mas daquelas que possam definir a agenda política e incluir a questão ambiental como uma das prioridades nas políticas públicas.

A atuação dos conselhos municipais de meio ambiente é um recurso importante para enfrentar os problemas ambientais, organizando as demandas sociais na agenda política de forma mais democrática. Os conselhos indicam um caminho de descentralização da composição da agenda política e de participação popular nos assuntos comuns. A ação integrada do Estado e da sociedade civil aponta para a otimização das políticas públicas, dos programas e planos governamentais, na medida em que o cidadão sinta a legitimidade das decisões e passe a zelar pelo cumprimento das políticas. Os conselhos são, dependendo das características de seu funcionamento, espaços de reforço da atitude cívica.

Assim, se objetivou a caracterização dos conselhos municipais no Estado do Paraná. Verificouse a sua existência, suas principais funções, sua composição e sua atividade, através dos dados da Pesquisa de Informações Básicas Municipais do IBGE. Assim, a investigação centra-se sobre o importante desenvolvimento no território paranaense destes aparatos institucionais participativos, acreditando na potencialidade e representatividade dos conselhos de meio ambiente na definição da agenda política dos municípios.

Os conselhos representam um dos caminhos disponíveis para o desenvolvimento do espaço político local e para um autêntico re-despertar da sociedade civil enquanto comunidade política. A participação mais direta traz consigo a requalificação do poder público, devolvendo-o à sociedade e ampliando seu poder decisório além do sistema representativo para tratar das questões municipais.

As potencialidades da Geografia Política no estudo da questão ambiental

Demonstrar-se-á, nessa primeira parte, que embora o caráter interdisciplinar da temática ambiental seja ressaltado como uma qualidade admirável, ele esconde uma série de problemas. Dentre os principais está a visão naturalista que aponta o homem como um mero fator ou variável de desequilíbrio ("a ação antrópica") na questão ambiental. Neste sentido, se minimiza toda a complexidade da ação social e o seu poder transformador sobre o espaço geográfico. Assim, propõe-se, neste artigo, recuperar a problematização do social e do territorial na questão ambiental através das potencialidades da Geografia Política.

A questão ambiental é exemplo pleno de objeto interdisciplinar, compondo as preocupações de pesquisadores em diversos ramos do conhecimento: na biologia, na geografia (Becker et al., 
1997; Coelho Netto, 1995), na sociologia (Ferreira, 1996, Moraes, 1994), na ciência política (Pádua, 1991; Lopes, 1994), na história (Dean, 1996), etc. Entretanto, aquilo que num primeiro momento é apresentado como qualidade positiva (a interdisciplinaridade das questões ambientais), esconde uma série de problemas.

O primeiro é o tratamento confuso entre diferentes especialistas, com formações díspares e com grande carga de preconceitos com as outras áreas (Moraes, 1994: 32). Nos fóruns de discussão sobre o meio ambiente, a divergência na utilização de conceitos e linguagens dificulta a progressão do conhecimento. Nos encontros dos pesquisadores se configura uma "Torre de Babel", onde cada um fala sua própria língua, sem entender a dos demais. Desse modo, o conhecimento relativo à temática ambiental não se beneficia da diversidade de disciplinas que atuam sobre o tema. Torna-se, na verdade, prisioneiro de métodos díspares, lacunas conceituais e linguagens distintas, diante da carência do desenvolvimento de bases teóricas e metodológicas que permitam aproveitar o conjunto dos conhecimentos produzidos sobre o assunto. É necessário, portanto, adotar medidas para o aproveitamento dessa rica interdisciplinaridade, como uma padronização mínima da linguagem e um aclaramento conceitual afim de melhor apreender a vasta produção sobre o assunto (Carvalho,1992; Moraes, 1994).

A interdisciplinaridade da questão ambiental carece de um desenvolvimento de cunho epistemológico. Segundo Moraes (1994), essa temática emergiu num plano bastante técnico nos momentos iniciais de seu estudo científico, deixando de lado reflexões metodológicas e epistemológicas. Estas são extremamente necessárias para qualquer área, principalmente para aquelas recentes, pois a epistemologia se encarrega do balanço crítico das novas técnicas, dos novos paradigmas e das novas teorias. Enfim, deste desenvolvimento depende o progresso das ciências na abordagem da questão ambiental. Alguns reconhecidos esforços de discussão teórico-metodológica já vêm sendo desenvolvidos, como os de Enrique Leff, em Epistemologia Ambiental (2001a) e Saber Ambiental (2001b). Este autor problematiza a questão ambiental retirando-a da exclusividade de seu tratamento pelas ciências naturais e aponta para uma hermenêutica necessária, que aceita a complexidade envolvida no tema e não propõe um conhecimento uno sobre o meio ambiente, refutando as simplificações.

De acordo com Moraes (1994), do conjunto de estudos que tratam da problemática ambiental pode-se identificar três orientações principais:

- O naturalismo, que desconsidera a dimensão social. Os seus adeptos vêem o homem apenas como fator de alteração no equilíbrio do meio. É utilizado um discurso "holístico" que retoma a ótica naturalista e trata as relações sociais e a relação homem-natureza pela menção reducionista da "ação antrópica";

- O tecnicismo, que desconsidera as implicações políticas das questões ambientais e estabelece a tecnologia como algo acima dos conflitos e da disputa de interesses do jogo social.

- O romantismo, que peca por uma excessiva politização, se manifestando no preservacionismo radical, que coloca a natureza acima do homem.

Na geografia, que se destaca diante das ciências sociais no estudo do meio ambiente por ter como um de seus temas clássicos a relação homem-natureza, é visualizada com bastante freqüência a orientação naturalista. $\mathrm{O}$ discurso holístico preconizado por essa vertente empobrece a análise da questão ambiental na medida em que o conceito de "ação antrópica" fica muito aquém de poder explicar toda a complexidade das relações políticas, sociais e econômicas que fazem parte da configuração de um espaço vivido, como indicou Moraes (1994).

A menção do termo "ação antrópica" na geografia estaria adequada quando nos referimos, por exemplo, à análise dos processos físicos que podem ser acelerados pelas atividades do homem, como a relação entre técnicas empreendidas em determinada cultura no campo e os processos erosivos. 
Contudo, o termo "ação antrópica" não é adequado, por exemplo, para a análise dos complexos problemas ambientais de uma cidade. Portanto, adotá-lo indiscriminadamente para explicar quaisquer danos relacionados à natureza, parece simples demais para um espaço que definido como uma estrutura social e instância da sociedade.

Enfatiza-se nesse trabalho, subvertendo a superficialidade da abordagem naturalista, tecnicista e romântica, a importância de uma reflexão fundamentalmente política e territorial, buscando-se na Geografia Política contribuições necessárias sobre as questões socioambientais.

Os conflitos ambientais são, na verdade, conflitos pela apropriação de um território, sejam para exploração, sejam para defini-lo enquanto área de proteção. Assim, revelam-se no cotidiano social e demonstram o papel chave da relação entre política (que gerencia os conflitos sociais) e território (base material destes conflitos) para a compreensão da questão ambiental. É importante considerar os conflitos ambientais como essencialmente sociais, pois englobam confrontos que não são entre o homem e a natureza, mas sim dos homens entre si. O que está em questão não é um jogo de ação e reação entre a sociedade e as forças naturais. $\mathrm{O}$ "furor vingativo" da natureza contra o homem ainda não foi comprovado cientificamente e, obviamente, não será, pois não há uma intencionalidade malévola inerente a um evento natural. Quando se fala em conflitos ambientais, o jogo de forças é dos homens entre si, pela apropriação e exploração de um território.

As ações de grupos ambientalistas, muitas vezes, se voltam contra a apropriação de um território por grupos econômicos ou por atores poderosos do jogo social. São objetos de disputa: áreas ainda não exploradas pelo mercado imobiliário, licença para atividades predatórias em determinados ambientes, áreas de mananciais que abastecem as cidades, áreas legalmente protegidas que é palco para atividades ilegais, entre outros.

Diferentes biomas e ecossistemas se transformaram em verdadeiras arenas de disputa de interesses que envolvem uma extensa pluralidade de atores nas mais diferentes escalas. Assim, as disputas por um território valioso de acordo com parâmetros econômicos ou culturais, podem englobar desde a comunidade local, as associações de moradores, os partidos políticos, até empresas transnacionais, organizações não-governamentais de abrangência internacional e os Estados.

A interação entre a estrutura física, as dinâmicas sociais e as relações desiguais de poder que influenciam o uso e o acesso aos recursos naturais faz da noção de território categoria fundamental na discussão da questão ambiental (Cunha e Coelho, 2003).

Outro relevante fundamento para os estudos relativos à questão ambiental é a política, pois é nesta que são tratados os conflitos sociais e territoriais intrínsecos à organização do espaço. Neste contexto, estando a Geografia Política compreendida na relação entre a política - expressão e modo de controle dos conflitos sociais - e o território - base material e simbólica da sociedade (Castro, 2005), ela torna-se um campo de extrema relevância para o tratamento da questão ambiental na atualidade.

Reforçamos nosso ponto de vista, relembrando a importância do Estado, tema clássico da Geografia Política, diante da problemática ambiental. De acordo com Bursztyn (1993, p.85):

Num mundo tendendo a reduzir a ação estatal, a questão ambiental se apresenta como importante exceção à regra. Em toda parte (...) foram sendo criadas estruturas governamentais voltadas para a regulamentação e para a fiscalização das atividades causadoras de danos ao meio ambiente.

Portanto, enquanto numerosos países adotam experiências desestatizantes, a ampliação das instituições regulamentadoras de caráter ambiental surge como uma importante reação às tendências do "Estado mínimo".

Para compreender a entrada da demanda ambiental na agenda política recorreremos às mudanças no pensamento ambientalista e o surgimento dos movimentos ambientalistas, assim como, a transformação destas demandas em dois tipos principais de ações estatais: as regulamentações e as novas instituições. Estes serão os temas abordados a seguir. 


\section{FASE DE TRANSIÇÃO: DO PENSAMENTO PRESERVACIONISTA AO SOCIOAMBIENTALISMO}

Há uma grande variedade de termos utilizados para designar as diferentes fases do ambientalismo e seu desenvolvimento. Diante das diferentes abordagens chega-se a um importante consenso: de que são duas, as fases que caracterizam o desenvolvimento do pensamento ambientalista, com qualidades distintas e bem delineadas. Alguns autores para defini-las utilizam os termos preservacionismo e conservacionismo (como, por exemplo, Cunha e Coelho, 2003), outros adotam o conservacionismo e o ambientalismo social (por exemplo, Lopes, 1994).

Adotar-se-á aqui os termos preservacionismo e socioambientalismo por algumas razões:

- Por uma possível confusão entre os significados de preservação e conservação. Inicialmente, no pensamento ambientalista, se defendia a não intervenção do homem nos ecossistemas naturais. Assim, defendia-se a preservação. Por outro lado, a conservação corresponde ao manejo dos recursos naturais com o objetivo de obter níveis ótimos de produção sem ameaçar a reposição de seus estoques (Cunha e Coelho, 2003). Assim, torna-se equivocado usar o termo conservacionismo para designar a primeira fase do ambientalismo;

- Utilizar-se-á o termo socioambientalismo para a segunda fase, não só a fim de evitar a confusão entre os termos mencionados acima, mas pretendendo reforçar o papel central da sociedade nas transformações da fase recente do movimento, bem como a incorporação da temática ambiental junto às lutas sociais.

O movimento ambientalista mundial esteve marcado desde seu início, no final do século XIX, até meados das décadas de 1960 e 1970 pela predominância do pensamento preservacionista. O preservacionismo tem como objetivo a manutenção do equilíbrio de ambientes naturais ameaçados pela expansão urbano-industrial (Lopes, 1994). O homem é considerado como fator de desequilíbrio em relação aos ecossistemas naturais.

As demandas do movimento visavam a proibir o acesso do homem e de suas atividades predatórias nas áreas ecologicamente preservadas. Este pensamento concebia a humanidade como inerentemente predatória, sendo contrário ao seu crescimento, nos planos técnicos, econômico e populacional (Lopes, 1994).

Para os preservacionistas, o meio ambiente ainda era visto como um bem extremamente ligado aos interesses daqueles que o utilizam e não como um bem pertencente à sociedade como um todo. Desse modo, as conseqüências da degradação ambiental atingiriam "interesses socialmente definidos (populações que usam recursos naturais para seu sustento ou lazer) e geograficamente delimitados (pela área relativa aos patrimônios naturais ameaçados)" (Lopes 1994: 10).

As políticas ligadas a essa tradição corresponderam a medidas regulatórias, que proibiam ou impediam o consumo e uso dos recursos naturais. Como exemplo, há as estações ecológicas, cuja finalidade primária foi a realização de pesquisas e de campanhas educativas de conservação da natureza, e as reservas ecológicas, visando exclusivamente a preservação da flora e da fauna (Moreira, 1992 apud Lopes 1994).

O socioambientalismo, pensamento que substituiu o preservacionismo, surgiu no período pós-guerra com o fenômeno da "megalopolização", que atraiu contingentes majoritários das populações para cidades cada vez maiores (Lopes, 1994). Graves problemas ambientais urbanos foram revelados, se transformando em custos sociais, na medida em que a população foi mais duramente atingida por enchentes, deslizamentos, poluição do ar e das águas, etc. A sociedade, a partir daí, passa a entender o meio ambiente como um bem público buscando uma nova orientação para suas demandas relativas à qualidade ambiental.

De acordo com os pressupostos socioambientalistas, as estratégias de conservação devem ser direcionadas para um manejo sustentado, não sendo correto, desta forma, excluir todos os interesses

Mercator - volume 8, número 17, 2009: set./dez. 
econômicos e a satisfação das necessidades básicas das populações locais (Saterson, 1994; Brown e Wickoff-Baird, 1994; Kaiser, 1999 apud Cunha e Coelho, 2003).

Deste modo, o pensamento socioambientalista mostra-se de acordo com as propostas de desenvolvimento sustentável, sendo necessária uma apropriação dos recursos naturais de maneira racional e igualitária, proporcionando aos atores sociais presentes e futuros a satisfação de suas necessidades e de seus interesses coletivos.

É nesta fase que a sociedade passa a reagir contra os problemas ambientais inserindo-os como temática de organizações não-governamentais, partidos políticos e associações. O Estado apresenta-se como instrumento fundamental para alcançar a exploração racional dos recursos naturais, o controle da degradação e a melhoria da qualidade ambiental.

Podemos dividir as reações do Estado em resposta às demandas da sociedade por proteção ao meio ambiente em duas maneiras gerais:

- sob a forma de regulamentações, quando legislações específicas são criadas visando o estabelecimento de normas e regras de uso e acesso aos recursos naturais;

- e sob a forma de criação de um aparato institucional, que objetiva basicamente garantir o cumprimento da legislação, a elaboração e a implementação das políticas públicas, além de possibilitarem a descentralização do processo decisório e de criação de canais de participação da sociedade.

Abordaremos adiante o arranjo institucional estatal relativo ao meio ambiente no Brasil, como maneira de observar o encaminhamento na evolução da institucionalização da questão ambiental.

\section{A INSTITUCIONALIZAÇÃO DA QUESTÃO AMBIENTAL NO BRASIL}

De acordo com Bursztyn (1993: 87): "No caso brasileiro, a ação do Estado no enfrentamento da questão ambiental remonta, no que diz respeito à criação de instituições específicas, ao início da década de 70". Durante a Conferência de Estocolmo em 1972, o Brasil co-liderou com a China a aliança dos países periféricos contrários a reconhecer a importância dos problemas ambientais (Viola, 1996). Devido a esta posição, o governo brasileiro sofreu diversas críticas internacionais e como resposta criou, no ano seguinte, 1973, a Secretaria Especial do Meio Ambiente (SEMA). Por mais de uma década esta instituição vegetou, num segundo plano, em termos de importância no conjunto das ações governamentais (Bursztyn, 1993).

A Política Nacional do Meio Ambiente, a partir da Lei $n^{\circ} 6.938$ de 1981, foi a primeira grande medida efetiva de introdução da questão ambiental nas agendas públicas do país e o primeiro passo para sua efetiva institucionalização. A partir daí, a legislação brasileira passou a reconhecer o meio ambiente como um conjunto e seus recursos como interdependentes. O que é contrário ao momento anterior, em que o mundo natural era percebido como uma realidade constituída por atributos independentes, que eram objetos de legislações específicas (Fuks, 1996), como os códigos florestal, das águas e das minas, de 1934.

O arranjo institucional ambiental brasileiro está estruturado sobre três sistemas de ação cooperada (o nacional, o estadual e o municipal), que agregam as demais instituições atuantes numa mesma escala e interagem entre si. Tendo como estrutura de base o Sistema Nacional do Meio Ambiente - SISNAMA, instituído também pela Lei $n^{\circ} 6.938 / 81$.

Destaca-se, nesse trabalho, dentro do conjunto de instituições brasileiras, o papel dos conselhos. Estes são importantes canais institucionais que possibilitam maior controle sobre as atribuições do poder público e que ampliam a participação da sociedade (Castro, 2003). Além disso, eles surgem como instituições-chave para a descentralização do processo decisório, pois incidem sobre todo o circuito de gestão de uma política pública desde a sua formulação até a sua implementação (Gohn, 1998 apud Castro, 2003). 
A criação do Conselho Nacional do Meio Ambiente - CONAMA, em 1981, num período de governo militar e poder altamente centralizado, representou um ponto de ruptura entre o pensamento preservacionista e o socioambientalismo, permitindo inclusive a participação da sociedade civil organizada. De acordo com Bursztyn (1993), a instituição do CONAMA, sob o prisma da gestão pública, é um marco do ambientalismo no país, já que exerce especificamente funções relativas à política ambiental, reunindo segmentos representativos dos poderes públicos em seus diferentes níveis.

A Constituição Federal de 1988 iniciou um processo de descentralização federativa das competências de políticas econômicas e sociais. O poder de legislar sobre a questão ambiental, anteriormente concentrado no nível federal, foi flexibilizado pela atual constituição que determinou que os estados e municípios pudessem também legislar por intermédio das Constituições Estaduais e Leis Orgânicas Municipais.

Assim, o processo de descentralização federativa, iniciado em 1988, possibilitou a institucionalização e difusão de conselhos municipais de meio ambiente na década de 1990 por todo o país. Estes representavam ainda em 1999, 21\% dos conselhos municipais adotados, refletindo o imperativo ainda recente da conservação do meio ambiente pela sociedade brasileira.

Segundo o IBGE (2008), os conselhos municipais de meio ambiente são espaços de participação social, negociação de demandas e interesses e mediação de conflitos, que vem se consolidando num conjunto expressivo de municípios brasileiros. A atuação dos conselhos municipais, mais próxima ao cotidiano social e a abertura para a participação da sociedade em escala local, resulta em uma grande potencialidade de equacionamento dos problemas ambientais. A ação integrada do Estado e da sociedade civil pode resultar em otimização das políticas públicas, dos programas e planos governamentais, na medida em que o cidadão sinta a legitimidade das decisões e passe a zelar pelo cumprimento das políticas.

Os conselhos estabelecem um novo formato de relação Estado e sociedade, institucionalizam a participação dos diversos segmentos da sociedade civil organizada e possibilitam a entrada em vigor de uma nova cultura cívica (IBGE, 2008). O conselho municipal é criado por lei elaborada e aprovada pela Câmara de Vereadores.

Segundo, Philippi Jr. et al. (1999): "O Conselho pode tornar-se um dos grandes auxiliares da administração na definição de planos, programas e projetos que atendem às demandas da sociedade".

\section{MÉTODOS E MATERIAIS}

Mediante a importância dos conselhos para o gerenciamento dos problemas ambientais, principalmente na escala local, a pesquisa se justifica. Reconhece-se aqui que a esfera política não pode ser negligenciada no tratamento da questão ambiental. Integra-se a isso que a política é o espaço por excelência da negociação das demandas. E que, por conseguinte, o conselho é um fórum de institucionalização das demandas da sociedade e uma efetiva forma de descentralização do poder decisório.

A escala local é aquela na qual a política se torna mais sensível ao cidadão. É no município que está o contato mais direto entre um ente federativo ( os outros são a União e as Unidades da Federação) e o cidadão comum. Se a responsabilidade pelo bem comum que é o meio ambiente seguro e devidamente conservado faz parte dos deveres de uma sociedade, nada mais coerente do que a abertura de espaços políticos no município em que a sociedade possa fazer valer essa responsabilidade.

Assim, se utiliza a Geografia Política como base para a compreensão do desenvolvimento e das características dos conselhos municipais de meio ambiente. Elege-se como área de estudo o Estado do Paraná, devido ao interesse de contribuir, enquanto, pesquisa realizada em uma Universidade estadual - Universidade Estadual do Oeste do Paraná - para revelar a institucionalização com 
caráter participativo da questão ambiental nos municípios, representada pelos conselhos municipais de meio ambiente.

A fonte dos dados utilizados no trabalho é o Perfil dos Municípios Brasileiros - MUNIC 2008, produzido pelo Instituto Brasileiro de Geografia e Estatística - IBGE. Este é caracterizado como pesquisa institucional e de registros administrativos da gestão pública municipal, tratando-se de um levantamento sobre a estrutura, a dinâmica e o funcionamento das instituições públicas municipais (IBGE, 2008). A análise é realizada por entrevista presencial com aplicação de questionário básico a pessoas posicionadas em setores ou instituições investigados, que detêm informações sobre os órgãos públicos e demais equipamentos municipais (IBGE, 2008).

Para os objetivos do trabalho, foram analisadas as informações sobre o tema meio ambiente, presentes no MUNIC 2008. Mais especificamente, trabalhou-se com dados sobre a existência de conselhos municipais de meio ambiente no Paraná, a data de sua criação, as características de seu funcionamento e a sua operacionalidade nos últimos 12 meses.

Analisou-se, portanto:

- A distribuição dos municípios com conselho de meio ambiente no território paranaense e a sua presença de acordo com a faixa populacional;

- $\mathrm{O}$ ano de criação do conselho, a fim de perceber os períodos de maior institucionalização da questão ambiental nos municípios através do viés participativo;

- Se ele é deliberativo e não apenas consultivo, se é normativo (c.1), se tem poder de fiscalizador (c.2), o que revela maior representatividade e poder dentro do processo decisório;

- Como é a sua composição, entre componentes do Estado e da sociedade civil, o que revela o grau de democratização da instituição. Se ele é Paritário, ou seja, constituído por $50 \%$ de representantes do Estado e 50\% da sociedade; ou se é composto por percentuais maiores de participantes do Estado ou da sociedade civil.

- E se realizou reunião nos últimos 12 meses, que indica o funcionamento efetivo da instituição.

\section{SITUAÇÃO DOS CONSELHOS MUNICIPAIS DE MEIO AMBIENTE NO PARANÁ}

Segundo os dados da MUNIC 2008 (IBGE, 2008) 47\% dos municípios brasileiros dispõem de conselhos municipais de meio ambiente. Sendo, no entanto, baixa a presença desses conselhos comparada com outros tipos (como os de Saúde - 98\%; Assistência Social - 93\%; Direitos da Criança e do Adolescente - 77\%; e Educação - 73\%). Segundo as grandes regiões, o Sul e o Sudeste apresentam os maiores percentuais de municípios com conselho de meio ambiente (respectivamente, $61,1 \%$ e $58,7 \%$ ). Bem acima do percentual nacional de $47,6 \%$.

O Paraná, particularmente, fica em posição intermediária, mais ainda abaixo do percentual nacional, em relação à existência de conselhos municipais de meio ambiente $-40,3 \%$. Abaixo na Região Sul, de Santa Catarina (57\%) e do Rio Grande do Sul (80.2\%). Este último com a maior participação relativa de municípios com este fórum (IBGE, 2008). Dentro da realidade brasileira, o Paraná progrediu bem mais do que outros estados, com destaque para a Região Nordeste (Piauí - 5,8\%, Paraíba - 12,1\% e Maranhão - 19,8\%).

Dos 399 municípios paranaenses, 161 criaram conselhos de meio ambiente. Na Figura 1, é possível observar a distribuição destes. Verifica-se que existem três padrões no quadro. O primeiro é de forte concentração da presença dos conselhos no eixo que liga o litoral à Região Metropolitana de Curitiba, seguindo na direção noroeste para Tibagi e oeste para Guarapuava. O segundo é de ausência destes aparatos institucionais no extremo sul e no Centro do território. O terceiro maior 
padrão por sua extensão dentro do Estado, que apresenta concentrações intermitentes, é o que engloba as Regiões Oeste, Sudoeste e as demais que compõe o Norte Paranaense.

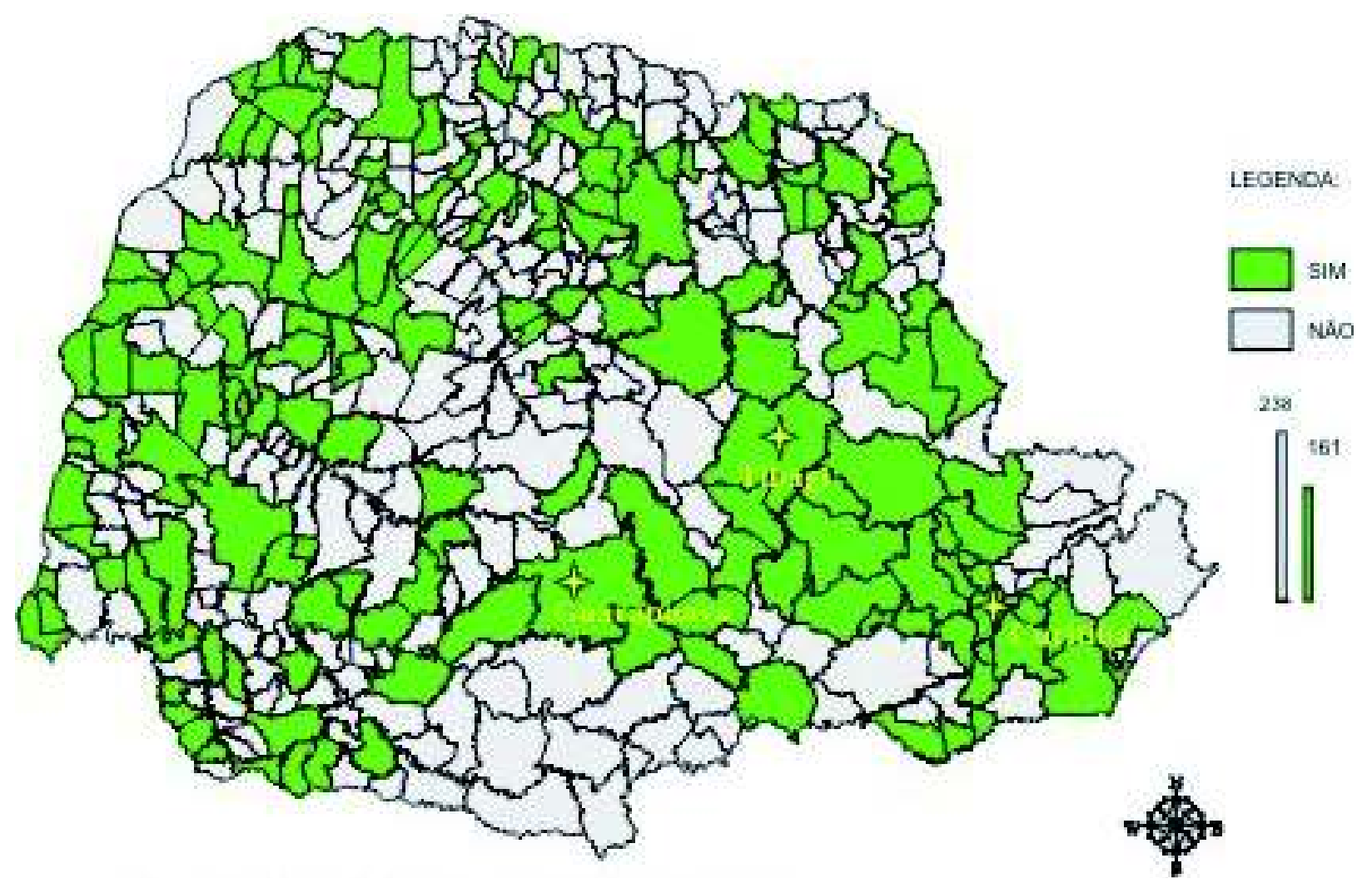

Figura 1 - .Existência de Conselho Municipal de Meio Ambiente, 2008. Municípios do Estado do Paraná. Fonte: IBGE - Perfil dos Municípios Brasileiros, MUNIC 2008.

Os resultados (Figura 2) mostram que os conselhos de meio ambiente estão mais presentes quanto mais populosos são os municípios. Nos menores, com até 10.000 habitantes, a presença é em apenas um quarto do total de 209 municípios (ou seja, 52 deles). Esse percentual vai aumentando até a faixa entre 100.001 a 200.000 habitantes. Há uma exceção apenas nos maiores municípios do Estado, já que um deles (Colombo, com 241.505 habitantes) não estabeleceu o conselho de meio ambiente até o final da pesquisa MUNIC 2008.

Com relação ao ano de criação dos conselhos de meio ambiente, pode-se observar na figura 3, que a quase totalidade destes está entre as décadas de 1990 e 2000. Se na década de 1990, são criados 37 conselhos municipais, o grande salto fica para a década de 2000, que embora não finalizada já apresenta a criação de 122 conselhos. Assim, reforça-se a idéia de que a democratização e a participação popular na gestão do meio ambiente na escala local é um fenômeno recente, ainda em processo de criação e estabelecimento. É inegável que a criação do SISNAMA, que possibilitou a integração de instituições nas diferentes esferas de poder, e os avanços da Constituição Federal de 1988 auxiliaram a municipalização da questão ambiental, possibilitando o processo de descentralização do poder decisório. Mas esse contínuo processo, mesmo em escala local, vem a ser paulatinamente desenvolvido, sendo criados mais recentemente espaços de discussão e apresentação de demandas - os conselhos, que apontam para uma gestão do ambiente mais autônoma nessa importante escala de poder político que é o município. 


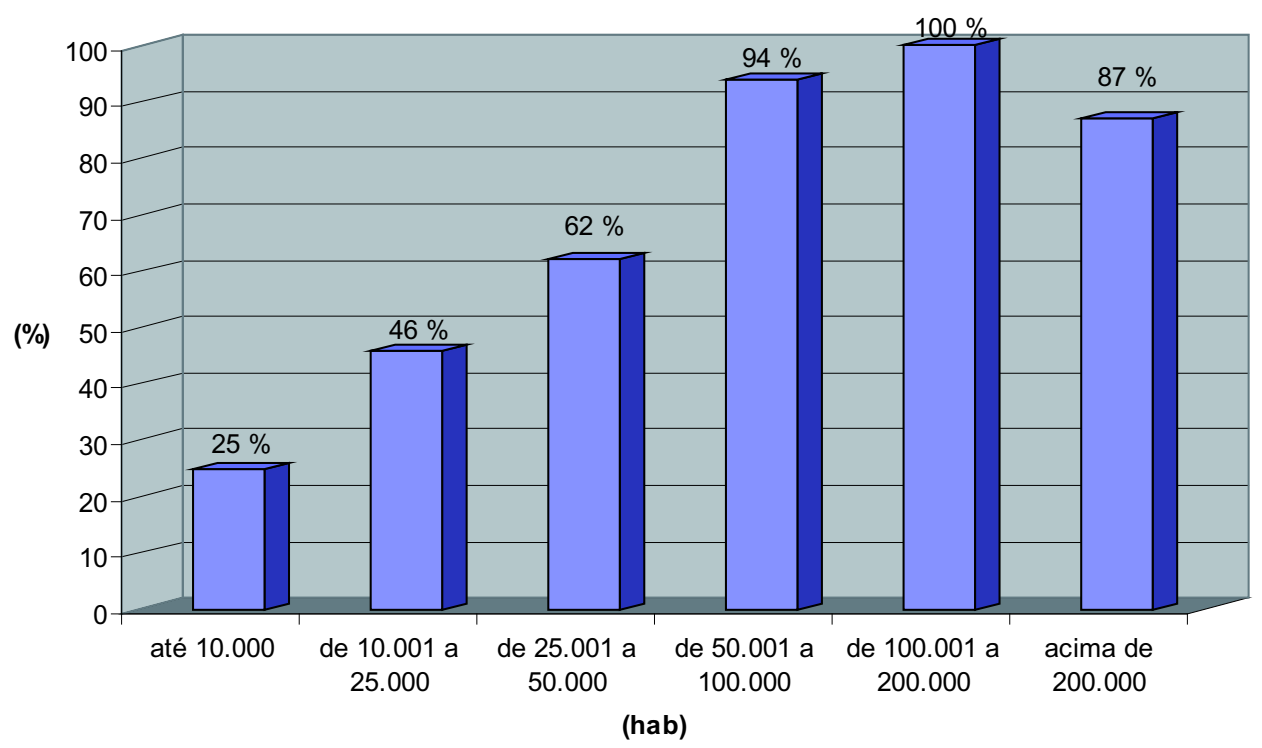

Figura 2 - Percentual de municípios com Conselho Municipal de Meio Ambiente, segundo as classes de tamanho da população, 2008. Municípios do Estado do Paraná.

Fonte: IBGE - Perfil dos Municípios Brasileiros - MUNIC 2008

O comportamento paranaense na criação dos conselhos acompanha o nacional, que, segundo o IBGE (2008), teve um tímido crescimento até 1996. Entre 1997 e 2007 se estabeleceram boa parte, $85,2 \%$, do total dos conselhos no país. Como foi revelado nos dados acima, no Paraná, o número de conselhos criados na década de 2000 , representa aproximadamente $75 \%$ do total.

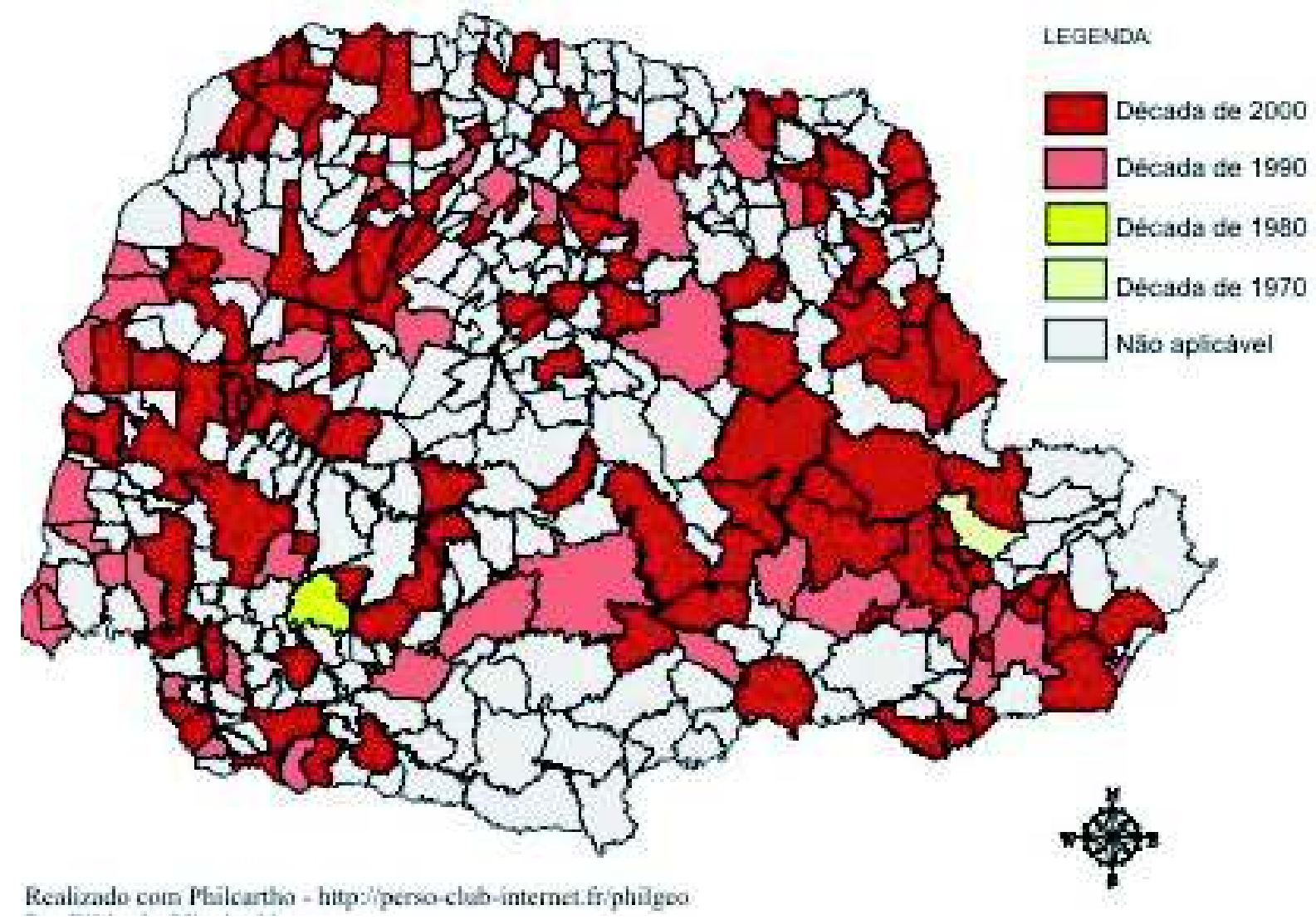

Figura 3 - Período de Criação do sConselhos de Meio Ambiente. Municípios do Estado do Paraná. Fonte: IBGE - Perfil dos Municípios Brasileiros, MUNIC 2008. 
Após a apresentação da situação da existência e da criação dos conselhos municipais, é possível nos ater a aspectos mais específicos, como o das suas características. Do total dos conselhos municipais do Estado do Paraná, nota-se que a maioria (70\%) é deliberativa, ou seja, não só é consultada. Eles tomam decisões, o que é um fato bastante positivo. Têm o poder de decidir sobre a implantação de políticas e a administração de recursos. Os membros de um conselho não-deliberativo, apenas consultivo, somente estudam e indicam ações ou políticas (IBGE, 2008).

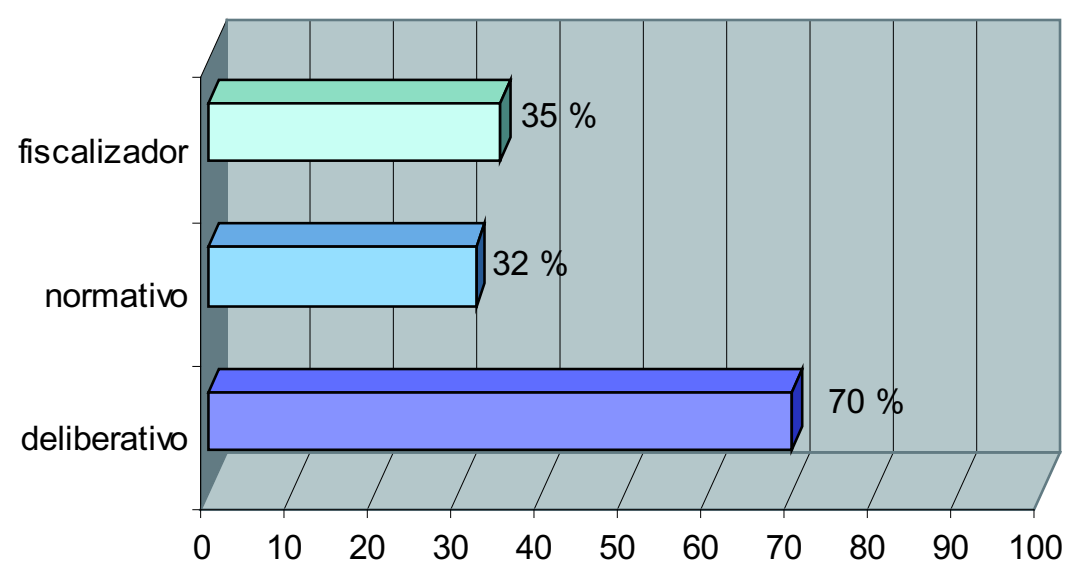

(\%)

Figura 4 - Características dos Conselhos Municipais de Meio Ambiente, 2008 . Estado do Paraná. Fonte: IBGE - Perfil dos Municípios Brasileiros - MUNIC 2008

Menos da metade, porém, estabelece normas e diretrizes para as políticas, além de não ter poder fiscalizador. O caráter normativo não indica que o conselho terá a função de criar leis (responsabilidade da Câmara de Vereadores), contudo pode sugerir a criação, bem como a adequação e a regulamentação das já existentes, por meio de resoluções (IBGE, 2008). Assim, o conselho com poder normativo constitui importante aliado e facilitador das ações do executivo e do legislativo municipal.

Ser fiscalizador, não significa que o conselho terá poder de polícia, mas que pode indicar ao órgão ambiental municipal a fiscalização de atividades poluidoras, da implementação de políticas e administração de recursos (IBGE, 2008). Configura, então, auxílio importante para a manutenção da qualidade ambiental no município.

A questão da paridade na composição do conselho, de ter ao menos metade dos participantes da sociedade civil e outra metade do Estado, é essencial para a representatividade do fórum. Para ser uma instituição de promoção da participação popular na gestão ambiental é requerido que a absorção das demandas populares seja progressivamente maior. Assim, analisou-se a composição dos conselhos como variável fundamental de sua existência e funcionamento visando consolidarse como fórum participativo (Figura 5). Observa-se que metade dos conselhos possui composição em partes iguais entre Estado e sociedade civil, o que é condição para que o município exerça o licenciamento ambiental de atividades e a cobrança de taxas, de acordo com as resoluções do CONAMA ( $\left.n^{\circ} 237\right)$. O quadro é positivo, pois mais de oitenta por cento, possui ao menos metade de sua composição da sociedade civil. 


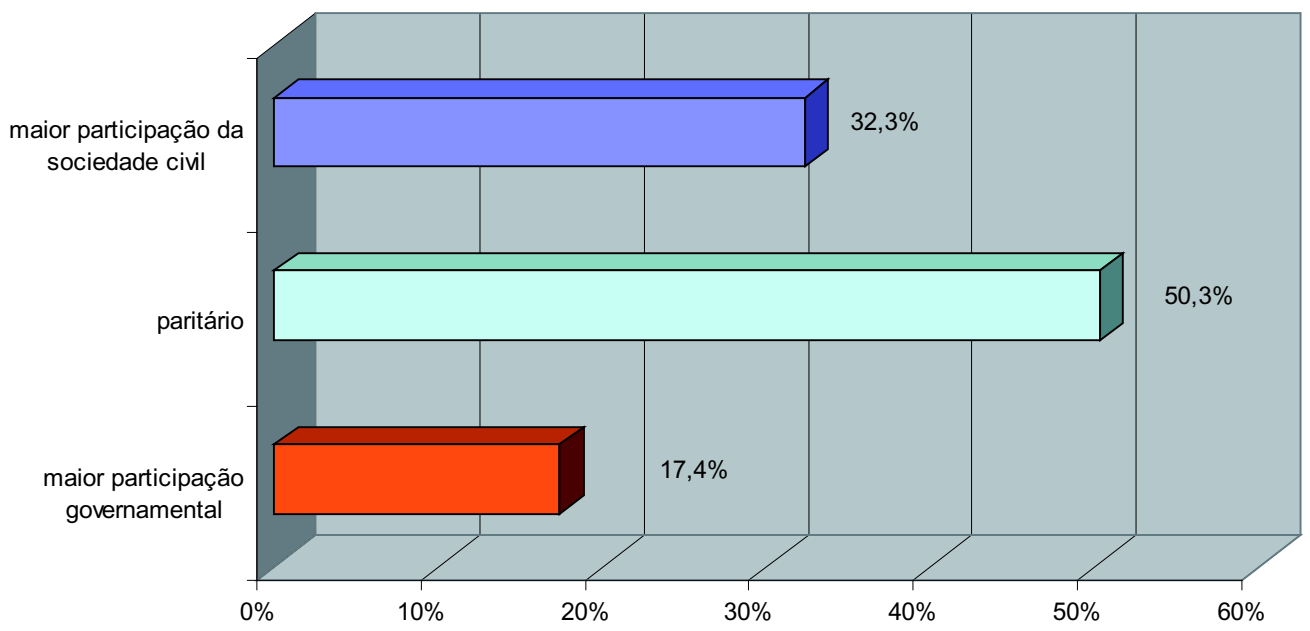

Figura 5 - Composição dos Conselhos Municipais de Meio Ambiente, 2008. Estado do Paraná Fonte: IBGE - Perfil dos Municípios Brasileiros - MUNIC 2008

A verificação das reuniões nos últimos 12 meses também foi importante variável, a fim de revelar se o conselho tem operacionalidade ou não para o município, ou apenas existe formalmente. A efetividade de operação dos conselhos faz parte de aproximadamente $72 \%$ do total dos fóruns. Contudo, quase 30\% deles não realizaram uma única reunião nos últimos 12 meses, denunciando uma existência mais formal do que real (Figura 6).

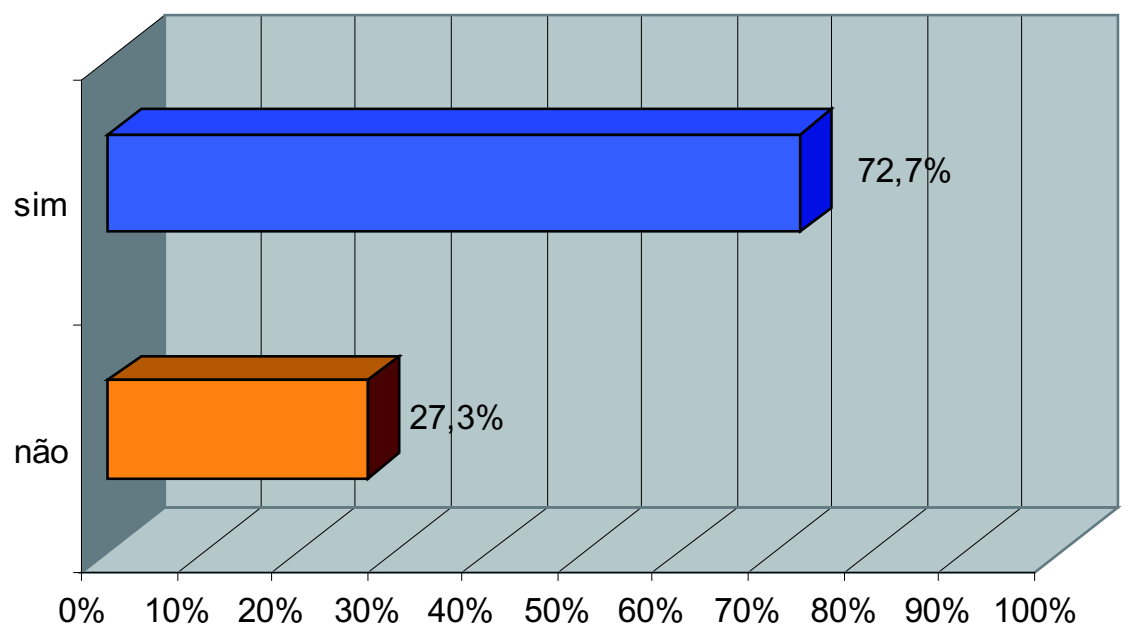

Figura 6 - O Conselho realizou reunião nos últimos 12 meses, 2008. Municípios do Estado do Paraná. Fonte: IBGE - Perfil dos Municípios Brasileiros - MUNIC 2008

A partir dos dados mencionados acima, apresentar-se-á nesse trabalho uma qualificação quanto à capacidade de atuar dos conselhos municipais de meio ambiente no Paraná, baseado nas seguintes características: se realizou reuniões nos últimos 12 meses; se é deliberativo ou não; se é normativo; se é fiscalizador; e se possui maior participação da sociedade. Quanto mais funções atribuídas ao conselho, maiores são as suas possibilidades de intervenção na realidade do município e maior é a autonomia para atender demandas da sociedade (Figura 7). 
Verifica-se que os municípios onde houve ausência de reuniões durante os últimos 12 meses (a) estão diversificadamente distribuídos no território paranaense. Por outro lado, existem dois pólos bem positivos de concentração conselhos municipais de meio ambiente. São municípios que apresentam conselhos com três funções: as funções de deliberação, normatização e fiscalização (e), ou que reúnem as 3 funções mais a composição de $50 \%$ ou mais pela sociedade civil (f). O primeiro pólo compreende quatro municípios no nordeste do estado, na microrregião de Jaguariaíva: Sengés, Arapoti, São José da Boa Vista (e) e o município sede (f). Do segundo pólo, no contato entre as mesorregiões centro oriental e Noroeste Paranaense, fazem parte: Cianorte, Ararunas, Tuneiras do Oeste, Janiópolis, Terra Boa, Jussara e Japurá (e), além de Indianópolis e Goioerê (f).

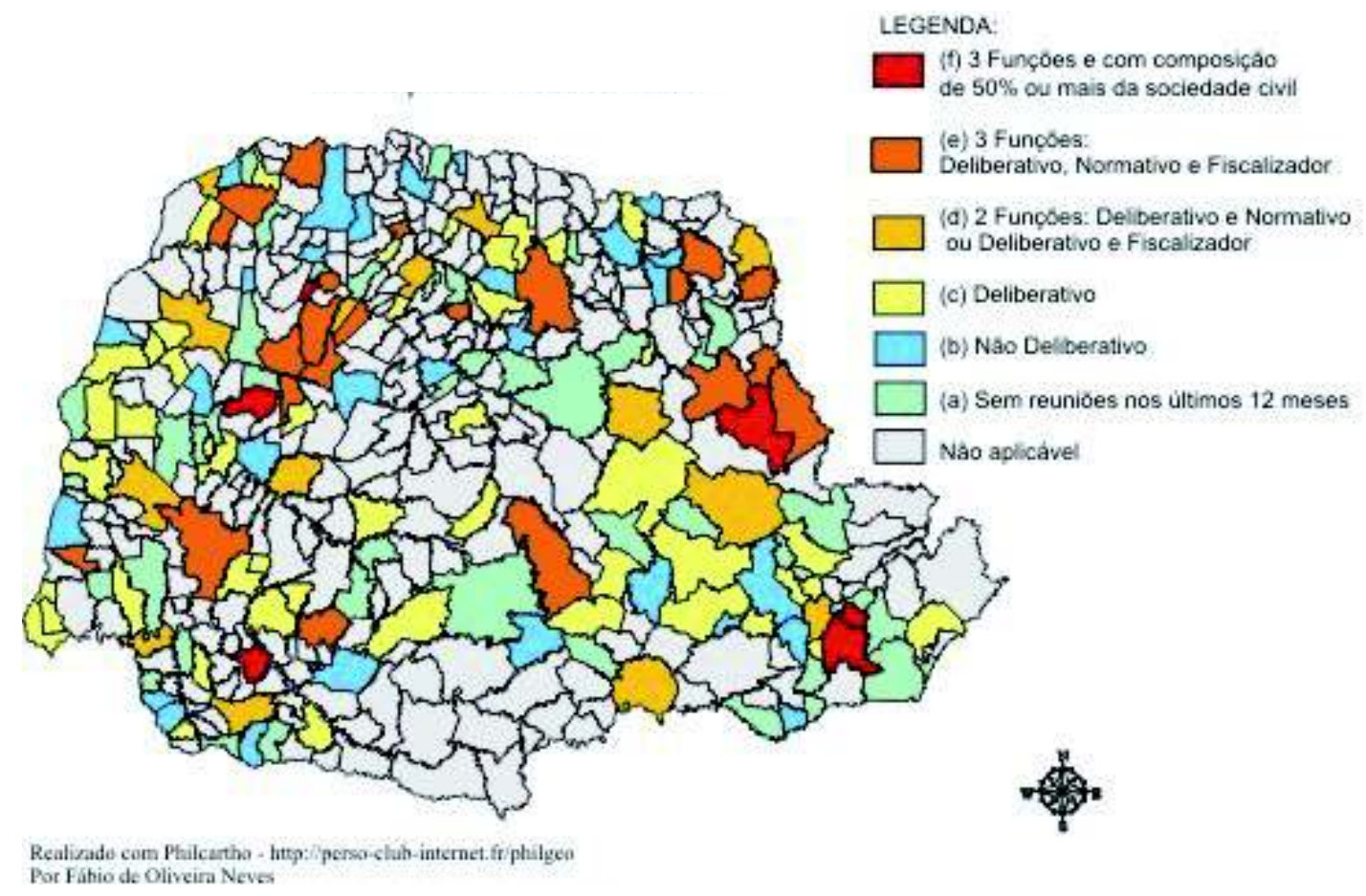

Figura 7 - Características dos Conselhos, 2008. Municípios do Estado do Paraná. Fonte: IBGE - Perfil dos Municípios Brasileiros - MUNIC 2008

A região metropolitana de Curitiba apresenta grande variedade na qualificação de seus conselhos. Destacam-se positivamente São José dos Pinhais e Piraquara (f), além da capital (e).

Londrina, segunda cidade mais populosa do estado, também se destaca, com um conselho que engloba três funções (e). Alguns municípios do seu entorno apresentam conselhos deliberativos (c).

Nos outros municípios mais populosos do Paraná a situação é de qualidade decrescente na seguinte ordem: Cascavel (e), Maringá (d), Foz do Iguaçu e Ponta Grossa (c).

Há um eixo bem nítido de qualidade intermediária entre Marechal Cândido Rondon (c) e Rio Bonito do Iguaçu (e), que passa por Toledo (d) e Cascavel (e) e outros municípios com conselhos deliberativos (c).

Outras áreas com alguns destaques positivos (d; e) estão na mesorregião noroeste: Umuarama e Porto Rico (d); Santa Isabel do Ivaí, Loanda e Terra Rica (e); e no Norte Pioneiro: Carlópolis, Santo Antônio da Platina e Jundiaí do Sul (e) e Ribeirão Claro (d).

Alguns outros destaques mais isolados são: Missal (e), no Oeste; Dois Vizinhos, no Sudoeste (f); Atalaia e Jandaia do Sul (e), no Norte; e Prudentópolis (e), no Centro.

Ao analisar as características dos conselhos por faixa de população dos municípios (Figura 8) observa-se que destes, o pior quadro está na faixa entre 100.001 a 200.000 habitantes. Esta é uma faixa que apresenta comportamento incomum se compararmos com as demais. As demais faixas, 
dos menores, com até 25.000 habitantes, até aqueles entre 50.001 e 100.000 habitantes há uma clara melhora na qualificação dos conselhos. A faixa entre 100.001 e 200.000 habitantes rompe, portanto, com esse comportamento.

Dos conselhos dos menores municípios, cerca de $30 \%$ não se reúnem, cerca de $20 \%$ não deliberam. Somente um pequeno percentual de aproximadamente $20 \%$ deles possui duas ou mais funções.

$\mathrm{Na}$ faixa de população entre 10.001 e 25.000 habitantes, a situação também não é boa (mais de $20 \%$ não se reúnem e mais de $20 \%$ não deliberam). Há uma pequena melhora no topo da qualificação, aproximadamente $25 \%$ possuem mais de uma função (junto com a deliberativa).

Entre 25.001 e 50.000 habitantes, a situação melhora um pouco. Cresce o percentual dos municípios que possuem mais de uma função e dos que somente deliberam, cerca de $30 \%$.

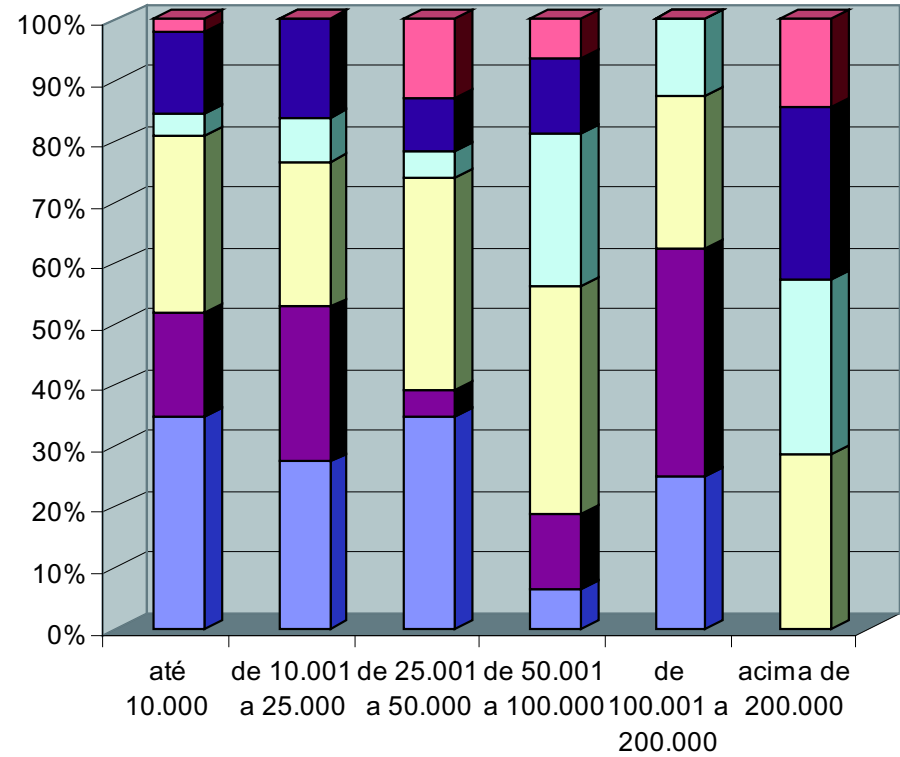

(hab)

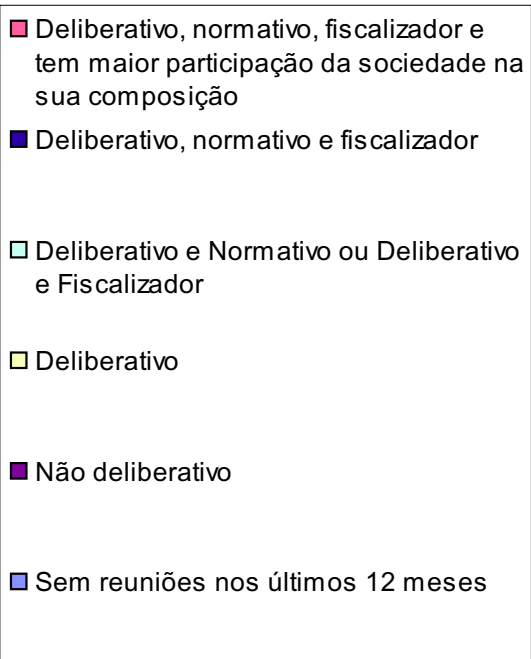

\begin{abstract}
Figura 8 - Características dos conselhos segundo as classes de tamanho da população dos municípios, 2008. Municípios do Estado do Paraná.

Fonte: IBGE - Perfil dos Municípios Brasileiros - MUNIC 2008
\end{abstract}

Entre 50.001 e 100.000 habitantes, os resultados melhoram visivelmente. $19 \%$ ou não deliberam ou não se reuniram nos últimos 12 meses. Mais de $81 \%$ possuem poder deliberativo, destes, $44 \%$ têm mais de uma das funções avaliadas.

A progressão na qualidade dos conselhos que acompanha o aumento da faixa populacional nos municípios do Paraná depara com uma situação incomum na faixa entre 100.001 e 200.000 habitantes. Esta concentra o maior percentual de conselhos que não deliberam: 37,5\%. E é a única faixa de população que não possui nenhum município com todas as funções. É, sem dúvida, a pior situação demonstrada pela pesquisa.

Dentre os sete municípios mais populosos do Estado do Paraná, não existe nenhum exemplo de ausência de reuniões nos últimos 12 meses. Todos deliberam. Mais de 70\% possuem mais de uma função. Mais de $40 \%$ possuem todas as funções. E 14,3\% têm grande participação popular.

Observa-se que o aparecimento dos melhores resultados (conselhos com três funções - deliberativo, normativo e fiscalizador - e com maior participação da sociedade) não está condicionado ao aumento do número de habitantes dos municípios. Dentre os conselhos em questão há até mesmo uma redução nos conselhos de melhor qualificação entre as faixas de 25.001 a 50.000 habitantes e 50.001 a 100.000 habitantes. Enquanto entre 100.001 e 200.000 habitantes há inclusive ausência destes. 


\section{CONSIDERAÇÕES FINAIS}

Atualmente, observa-se uma dinâmica de incorporação de espaços participativos que lidam com as questões do meio ambiente na escala local. Os conselhos representam espaços privilegiados da democratização do processo decisório das políticas e regulamentações municipais. Além disso, eles também participam do fortalecimento da cultura cívica, porque incorporam a sociedade civil nos espaços político-institucionais. Se na escala local concretiza-se o exercício da cidadania e se o município representa o espaço mais próximo da política para os cidadãos, os conselhos surgem como instrumentos fundamentais para tal exercício.

No âmbito do arranjo institucional paraense, há uma ausência considerável da existência de conselhos municipais de meio ambiente. Aproximadamente $60 \%$ dos municípios ainda não possuem conselho. Este resultado o distancia dos outros estados da Região Sul do Brasil, neste critério, que possuem maiores percentuais de presença de destes conselhos.

Os resultados demonstram que o surgimento dos conselhos municipais de meio ambiente é um fenômeno recente, das últimas três décadas. No caso específico do Paraná, 112 dos 161 conselhos municipais surgiram na década de 2000. Conclui-se que a participação popular e a democratização na composição da agenda ambiental dos municípios paranaenses é, em geral, um processo novo, em desenvolvimento e consolidação. É uma indicação de que aumentam as possibilidades de atender às demandas ambientais da população.

Ainda não se pode comparar o desenvolvimento do número de conselhos municipais de meio ambiente com outros como os de saúde e educação, porque os primeiros são derivados de demandas mais recentes, assim, de desenvolvimento mais tardio no arranjo institucional.

Em relação às características dos conselhos, a maioria dos existentes no Paraná tem poder de decidir sobre a implantação de políticas e a administração de recursos. São, portanto, deliberativos (aproximadamente 70\% deles). O que é um dado positivo.

Entretanto, qualquer otimismo precipitado deve ser evitado. Menos da metade estabelece normas e diretrizes para as políticas (normativos), além de não possuir poder fiscalizador.

Outro resultado positivo deve ser visualizado no critério de composição dos conselhos. Há forte participação social em cerca de $80 \%$ dos conselhos municipais de meio ambiente (com participação da sociedade civil equivalente a 50\% ou mais na composição do fórum).

A maior parte deles (cerca de 70\%) realizou ao menos uma reunião nos últimos 12 meses, demonstrando alguma atividade. O que pode ser lido como um dado positivo, apesar de reconhecermos a fragilidade desse dado da pesquisa utilizada, que inclui tanto os conselhos que fizeram apenas uma reunião em todo o ano junto com outros que podem ter feito um maior número.

Os resultados também deixaram uma provocação para pesquisas posteriores: o porquê dos maus resultados dos conselhos em municípios com população entre 100.001 e 200.000 habitantes. São poucos conselhos que agregam duas funções (menos de 20\%), nenhum que agrega três funções e mais da metade deles não deliberativo ou que não realizou reuniões nos últimos 12 meses. Estes dados indicam a necessidade de aprofundar os estudos regionais e locais nesta temática para entender essa lógica.

É necessário, por fim, ressaltar a necessidade dos estudos sobre instituições e território para compreensão da questão ambiental, notadamente no Estado do Paraná. Tentando compreender a distribuição, o surgimento e a qualidade dos conselhos no território, como aparatos de potencial incorporação das demandas ambientais nas agendas políticas.

\section{REFERÊNCIA BIBLIOGRÁFICA}

BECKER, Bertha e MIRANDA, Mariana. A Geografia Política do Desenvolvimento Sustentável. Rio de Janeiro, Editora UFRJ, 1997.

BURSZTYN, Marcel. Estado e Meio Ambiente no Brasil: desafios institucionais. In: BURSZTYN, Marcel (org.), Para Pensar o Desenvolvimento Sustentável. São Paulo: Editora Brasiliense, 1993, p. 83-101.

Mercator - volume 8, número 17, 2009: set./dez. 
CARVALHO, Isabel Cristina Moura. Educação, Meio Ambiente e Ação Política. In: ACSELRAD, Henri (Org.), Meio Ambiente e Democracia. Rio de Janeiro: IBASE, 1992, p. 33-42.

CASTRO, Iná Elias de. Instituições e Território. Possibilidades e limites ao exercício da cidadania. Revista Geosul, v.19, 16-32, 2003.

CASTRO, Iná Elias de. Geografia e Política: território, escalas de ação e instituições. Rio de Janeiro: Bertrand Brasil, 2005.

COELHO NETTO, Ana Luiza. Meio Ambiente e Natureza: Concepções e Abordagens na Geografia. In: A Geografia e as Transformações Globais. Conceitos e temas para o ensino. Anais "O Ensino da Geografia de $\mathbf{1}^{\mathbf{0}} \mathbf{e} \mathbf{2}^{\mathbf{0}}$ graus frente às transformações globais". Rio de Janeiro: Editora da UFRJ, p. 45-60, 1995.

CUNHA, Luís Henrique \& COELHO, Maria Célia Nunes. Política e Gestão Ambiental. In: GUERRA, Antônio José Teixeira e CUNHA, Sandra Baptista (Orgs.), A Questão Ambiental. Diferentes abordagens. Rio de Janeiro: Bertrand Brasil, 2003, p. 43-80.

DEAN, Warren. A Ferro e Fogo: a história e a devastação da Mata Atlântica brasileira. São Paulo: Companhia de Letras, 1996.

FERREIRA, Leila da Costa. A busca de alternativas de sustentabilidade no Poder Local. In: FERREIRA, Leila da Costa e VIOLA, Eduardo (Orgs.), Incertezas de Sustentabilidade na Globalização. Campinas: Editora da UNICAMP, 1996, p. 133-160.

FUKS, Mario. Do Discurso ao Recurso: uma análise da proteção judicial ao meio ambiente do Rio de Janeiro. In: FERREIRA, Leila da Costa e VIOLA, Eduardo (Orgs.), Incertezas de Sustentabilidade na Globalização. Campinas: Editora da UNICAMP, 1996, p. 189-216.

IBGE. Pesquisa de Informações Básicas Municipais - 2008. Perfil dos Municípios Brasileiros. Rio de Janeiro: IBGE, 2008.

LEFF, Enrique. Epistemologia ambiental. São Paulo: Cortez Editora, 2001 (a).

LEFF, Enrique. Saber Ambiental. $4^{\circ}$ ed. São Paulo: Editora Vozes, 2001 (b).

LOPES, Júlio Aurélio Vianna. Meio Ambiente e Políticas Públicas: tradição regulatória e aspectos redistributivos emergentes. Série Estudo, Rio de Janeiro - RJ: IUPERJ, 1994.

MORAES, Antonio Carlos Robert. Meio Ambiente e Ciências Humanas. São Paulo: Editora Hucitec, 1994 PÁDUA, José Augusto. O nascimento da política verde no Brasil: fatores exógenos e endógenos. In: LEIS, Héctor R. (Org.), Ecologia e Política Mundial. Petrópolis: Editora Vozes, 1991, p. 135-161.

PHILIPPI JR., Arlindo et al. Municípios e Meio Ambiente. Perspectivas para a municipalização da gestão ambiental no Brasil. Associação Nacional de Municípios e Meio Ambiente. São Paulo: ANMMA, 1999.

VIOLA, Eduardo. A multidimensionalidade da globalização, as novas forças sociais transnacionais e seu impacto na política ambiental no Brasil, 1989-1995. In: FERREIRA, Leila da Costa e VIOLA, Eduardo (Orgs.), Incertezas de Sustentabilidade na Globalização. Campinas: Editora da UNICAMP, 1996, p. 15-65.

Trabalho enviado em setembro de 2009

Trabalho aceito em dezembro de 2009 